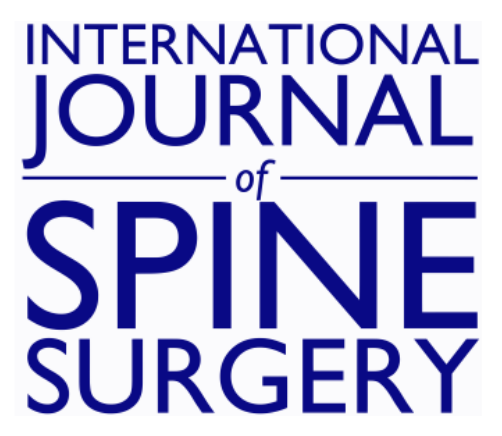

\title{
Cervical Disc Arthroplasty: An Update on Current Practices
}

\author{
Matthew Gornet \\ Int J Spine Surg 2020, 14 (s2) S2-S4 \\ doi: https://doi.org/10.14444/7085 \\ http://ijssurgery.com/content/14/s2/S2 \\ This information is current as of April 26, 2023.
}

Email Alerts Receive free email-alerts when new articles cite this article. Sign up at: http://ijssurgery.com/alerts 


\title{
Cervical Disc Arthroplasty: An Update on Current Practices
}

\author{
MATTHEW GORNET, MD \\ IJSS Section Editor, Guest Editor of Cervical Disc Arthroplasty Special Issue, The Orthopedic Center of St. Louis, Chesterfield, Missouri
}

Cervical disc arthroplasty (CDA) has been in use since the late 1990s for treatment of degenerative disc disease and is now considered an established alternative to anterior cervical discectomy and fusion (ACDF) for appropriately selected patients. $^{1-4}$ US Food and Drug Administration (FDA)-approved clinical trials have established that CDA and ACDF are at least equally safe and effective in treating symptoms associated with single- and 2-level cervical degenerative disc disease, and most studies report better outcomes on a variety of measures for CDA compared with ACDF. At least 7 different CDA devices in the United States have received marketing approval. Results of prospective and retrospective CDA studies have been published with follow-ups of 10 to 15 years. ${ }^{5-16}$ As a result of this large and growing body of evidence, more surgeons are choosing CDA for their patients. As a note, the procedure has been referred to by various terminology in the literature, including total disc replacement (TDR), cervical total disc replacement (cTDR), cervical disc replacement (CDR), CDA, and artificial disc replacement (ADR).

This special focus issue provides a basic overview of CDA and reviews the current status of the field, including several papers exploring expanded use criteria. In the first paper, Derman et al describe the rationale for CDA and trace the history of the development of the various devices. They discuss some of the well-known limitations of ACDF and the potential benefits of CDA in maintaining segmental motion. They describe the different devices as they have developed over time and review the current status of FDA-approved devices, including length of reported follow-up and a brief review of results.

Patwardhan and Havey provide a detailed look at the biomechanics of CDA, including prosthesis design features and surgical factors related to implantation that may influence the response of cervical segments after CDA. They note that the potential advantages of CDA are based on the premise that preservation of physiologic motions and load-sharing at the treated level would lead to longevity of the facet joints at the index level and mitigate the risk of adjacent segment degeneration. They review the different criteria that have been used to classify cervical disc prostheses designs and provide examples of prostheses with different design elements such as number of components. After reviewing the kinematics of healthy cervical spine segments, they explore how prostheses with different designs affect the quantity and quality of motion after CDA. Finally, they discuss the influence of surgical factors including prosthesis placement in the disc space, integrity of the posterior longitudinal ligament, and prosthesis disc height.

The widely accepted criteria for patient selection in the United States are based on the relatively narrow inclusion and exclusion criteria used in the clinical trials that led to FDA-approved indications and contraindications. Frank et al review these selection criteria as well as patient selection outside of the United States, which is, in general, less stringent. They address the question of whether it is time for a shift in US adoption of expanded indications for CDA and review the literature related to this. They discuss some of the more debated indications and contraindications for expanded selection criteria, including more than 2 levels, hybrid devices, revision of failed fusion, kyphosis, and other considerations.

Several CDA devices have undergone clinical trials and been FDA-approved for use at 2 levels. Goldstein et al review the mid- and long-term evidence from studies comparing CDA to ACDF. They discuss findings from 2 large randomized, prospective FDA IDE trials, the first with 5-year follow-up and the second with data published for 
both 7-year and 10-year follow-up. In addition, they also review a number of smaller or shorter-term studies of the use of 2-level CDA. They conclude that the results of randomized clinical trials suggest similar to improved patient reported outcomes for multilevel CDA versus ACDF, maintained out to 5 to 10 years, with lower rates of revision surgery at index and adjacent levels and lower rates of serious adverse device-related events with CDA.

Multilevel cervical degenerative disc disease in more than 2 segments poses treatment challenges. Although use of CDA at more than 2 levels has been limited in the United States, Gornet et al report their experience with 139 patients undergoing 3- or 4-level CDA. They evaluate patient-reported outcomes up to 7 years postoperative. Results are presented for Neck Disability Index, neck pain, arm pain, and Veterans Rand health survey physical and mental components, as well as heterotopic ossification, secondary surgeries, and patient satisfaction. The study found statistical improvement in patientreported outcomes with a low rate of secondary surgeries out to 7 years, suggesting that 3-and 4level CDA may be performed safely and effectively in appropriately selected patients.

Another area of possible expanded indications for CDA is in the use of cervical hybrid reconstructions. Scott-Young et al report their results using combined cTDR and ACDF, commonly referred to as cervical hybrid surgery. They prospectively collected data on 151 patients. Outcome measures included patient satisfaction, neck and arm pain scores, and Neck Disability Index as well as complication and re-operation rates. Findings lead them to conclude that cervical hybrid surgery for multilevel degenerative disc disease demonstrates favorable and sustained clinical outcomes at shortto mid-term follow-up.

Parish et al provide a summary review of the potential complications of CDA and discuss complication avoidance. They note that complications can be categorized as errors in patient selection or in surgical technique as well as those associated with an anterior cervical approach in general versus those specific to CDA. They discuss specific complications and cite literature regarding rates of occurrence, patient selection issues, and surgical technique. Some of the complications reviewed include subsidence and device migration or dislocation, heterotopic ossification, adjacent segment disease, dysphagia and vascular complications, and infec- tion. They conclude that complications uniquely associated with CDA are uncommon and can be mitigated by proper patient selection and attention to surgical technique.

Finally, Radcliff et al discuss the economics of CDR. They provide a review of the various methods used to determine cost-effectiveness and discuss the recent literature on cost-effectiveness of CDA versus ACDF. They note that recent studies using more robust methods than the older literature confirm that in properly selected patients, CDA not only results in superior clinical outcome, but also is less costly over a 7-year time horizon for patients with symptomatic degenerative disc disease than ACDF. They conclude that the primary driver of this difference in cost-effectiveness is the difference in secondary surgery rates.

The papers in this Focus issue, taken together, should provide the reader with a good overview of the current state of CDA, from the rationale for and biomechanics of CDA to patient selection, use at multiple levels, complications and complication avoidance, and the cost-effectiveness of this procedure compared with ACDF. The issue includes review and summary articles as well as several original clinical studies. We hope that this special collection of papers will provide you with the type of information that can contribute to your practice in terms of both treatment decisions and patient counseling.

\section{REFERENCES}

1. Joaquim AF, Makhni MC, Riew KD. Evidence-based use of arthroplasty in cervical degenerative disc disease. Int Orthop. 2019;43(4):767-775. doi:10.1007/s00264-018-04281-y

2. Xie L, Liu M, Ding F, et al. Cervical disc arthroplasty (CDA) versus anterior cervical discectomy and fusion (ACDF) in symptomatic cervical degenerative disc diseases (CDDDs): an updated meta-analysis of prospective randomized controlled trials (RCTs). SpringerPlus. 2016;5(1):1188. doi:10.1186/ s40064-016-2851-8

3. Gao F, Mao T, Sun W, et al. An updated meta-analysis comparing artificial cervical disc arthroplasty (CDA) versus anterior cervical discectomy and fusion (ACDF) for the treatment of cervical degenerative disc disease (CDDD). Spine. 2015;40(23):1816-1823. doi:10.1097/BRS.0000000000001138

4. Zhang Y, Liang C, Tao Y, et al. Cervical total disc replacement is superior to anterior cervical decompression and fusion: a meta-analysis of prospective randomized controlled trials. PLoS One. 2015;10(3):e0117826. doi:10.1371/journal. pone. 0117826

5. Badve SA, Nunley PD, Kurra S, Lavelle WF. Review of long-term outcomes of disc arthroplasty for symptomatic single 
level cervical degenerative disc disease. Expert Rev Med Dev. 2018;15(3):205-217. doi:10.1080/17434440.2018.1433533

6. Buttermann GR. Anterior cervical discectomy and fusion outcomes over 10 years: a prospective study. Spine. 2018;43(3):207-214.

7. Dejaegher $\mathrm{J}$, Walraevens $\mathrm{J}$, van Loon $\mathrm{J}$, et al. 10-year follow-up after implantation of the Bryan Cervical Disc Prosthesis. Eur Spine J. 2017;26(4):1191-1198.

8. Gornet M, Burkus JK, Shaffrey ME, et al. Cervical disc arthroplasty: 10-year outcomes of the Prestige LP cervical disc at a single level. J Neurosurg Spine. 2019;31(3):317-325. doi:10. 3171/2019.2.SPINE1956

9. Gornet M, Lanman TH, Burkus JK, et al. Two-level cervical disc arthroplasty versus anterior cervical discectomy and fusion: 10-year outcomes of a prospective, randomized investigational device exemption clinical trial. J Neurosurg Spine. 2019;31:508-518. doi:10.3171/2019.4.SPINE1915729.

10. Hisey MS, Zigler JE, Jackson R, et al. Prospective, randomized comparison of one-level Mobi-C cervical total disc replacement vs. anterior cervical discectomy and fusion: results at 5-year follow-up. Int J Spine Surg. 2016;10:10. doi:10.14444/ 3010. eCollection 2016

11. Janssen ME, Zigler JE, Spivak JM, et al. ProDisc-C total disc replacement versus anterior cervical discectomy and fusion for single-level symptomatic cervical disc disease: seven-year follow-up of the prospective randomized U.S. Food and Drug Administration Investigational Device Exemption study. J Bone Joint Surg Am. 2015;97(21):1738-1747.

12. Lavelle WF, Riew KD, Levi A, et al. 10-year outcomes of cervical disc replacement with the BRYAN ${ }^{\circledR}$ Cervical Disc: results from a prospective, randomized, controlled clinical trial. Spine. 2019;44(9):601-608. doi:10.1097/BRS.0000000000002907

13. Mehren C, Heider F, Siepe CJ, et al: Clinical and radiological outcome at 10 years of follow-up after total cervical disc replacement. Eur Spine J. 2016;26(9):2441-2449.

14. Pointillart V, Castelain JE, Coudert P, et al. Outcomes of the Bryan cervical disc replacement: fifteen year follow-up. Int Orthop. 2018;42(4):851-857.

15. Yang SD, Zhu YB, Yan SZ, et al. Anterior cervical discectomy and fusion surgery versus total disc replacement: a comparative study with minimum of 10-year follow-up. Sci Rep. 2017;7(1):16443.

16. Zhao Y, Zhang Y, Sun Y, et al. Application of cervical arthroplasty with Bryan Cervical Disc: 10-year follow-up results in China. Spine. 2016;41(2):111-115.

Disclosures and COI: Dr Gornet declares the following relationships: Bonovo - Stock; International Spine Orthopedic Institute - Stock; Medtronic - Consultant, royalties; Nocimed - Stock; Ouroboros - Stock; Paradigm Spine - Stock; RTI Surgical Holdings - Royalties; Kaliber - Stock Shareholder; Aesculap - Consultant.

Published 30 September 2020

This manuscript is generously published free of charge by ISASS, the International Society for the Advancement of Spine Surgery. Copyright (C) 2020 ISASS. To see more or order reprints or permissions, see http://ijssurgery.com. 